\title{
Conhecimentos mobilizados por professores ao interagir com materiais curriculares de Matemática
}

\author{
Katia Lima ${ }^{1}$ \\ Ana Lucia Manrique ${ }^{2}$
}

\begin{abstract}
RESUMO
Neste artigo nosso foco de análise refere-se aos recursos docentes, para o qual objetivamos identificar conhecimentos mobilizados por professores que ensinam Matemática ao interagir com materiais curriculares. Para isso, propomos a seguinte questão: Que conhecimentos são mobilizados por professores a partir dos diferentes tipos de usos que fazem dos materiais curriculares? Tomando como aportes teóricos os estudos sobre a relação professormaterial curricular e o modelo do conhecimento didáticomatemático do professor, fizemos uma metanálise do relatório de um projeto de pesquisa que teve como propósito compreender como professores de uma rede pública de ensino avaliavam materiais curriculares de Matemática. Os resultados mostram que os professores reproduzem, adaptam e improvisam ao utilizar os materiais curriculares nas situações reais de sala de aula, mobilizando seus conhecimentos principalmente referentes às categorias epistêmica e cognitiva do Conhecimento DidáticoMatemático.
\end{abstract}

PALAVRAS-CHAVE: Materiais curriculares. Relação professor-

\footnotetext{
${ }^{1}$ Doutora em Educação Matemática. Universidade Federal do Recôncavo da Bahia (UFRB), Amargosa, Bahia, Brasil. https://orcid.org/0000-0003-3857-6841. katialimaufrb@gmail.com.

${ }^{2}$ Doutora em Educação. Pontifícia Universidade Católica de São Paulo (PUC-SP), São Paulo, São Paulo, Brasil. Orcid: http://orcid.org/0000-0002-7642-0381. analuciamanrique@gmail.com.
} 
materiais curriculares. Conhecimento profissional docente. Educação Matemática.

Knowledge mobilized by teachers when interacting with

Mathematics curriculum materials

\begin{abstract}
In this article, our focus of analysis refers to the teaching resources, for which we aimed to identify knowledge mobilized by teachers who teach math when interacting with curriculum materials. To this end, we propose the following question: What kind of knowledge are mobilized by teachers from the different types of uses that they make of the curriculum materials? Taking as theoretical contributions the studies about the teacher-curriculum material relationship and the Didactic-Mathematical Knowledge model of the teacher, we did a meta-analysis of the report of a research project that had as purpose understand how teachers of a public school system evaluated mathematics curriculum materials. The results show that teachers reproduce, adapt and improvise when using curriculum materials in the real classroom situations, and mobilize their knowledge mainly referring to the epistemic and cognitive categories of Didactic-Mathematical Knowledge.
\end{abstract}

KEYWORDS: Curriculum materials. Teacher-curriculum materials relationship. Teaching professional knowledge. Mathematics Education.

Conocimiento movilizado por los profesores al interactuar con los materiales del plan de estudios de Matemáticas

\title{
RESUMEN
}

En este artículo, nuestro enfoque de análisis se refiere a los recursos de enseñanza, para los cuales apuntamos a identificar el conocimiento movilizado por los profesores que enseñan matemáticas al interactuar con los materiales curriculares. Para 
esto, proponemos la siguiente pregunta: ¿Qué conocimiento movilizan los professores de los diferentes tipos de usos que hacen de los materiales curriculares? Tomando como contribuciones teóricas los estudios sobre la relación profesor-material curricular y el modelo del conocimiento didáctico-matemático del profesor, realizamos un metanálisis del informe de un proyecto de investigación que tenía como objetivo comprender cómo los profesores de un sistema escolar público evaluaban los materiales curriculares de las matemáticas. Los resultados muestran que los docentes reproducen, adaptan e improvisan cuando usan materiales curriculares en situaciones reales del aula, movilizando su conocimiento principalmente en referencia a las categorías epistémicas y cognitivas del conocimiento didáctico-matemático.

PALABRAS CLAVE: Materiales curriculares. Relación profesormaterial curricular. Conocimiento profesional docente. Educación Matemática.

$$
* * *
$$

\section{Ideias iniciais}

A bibliografia internacional tem mostrado o uso de materiais curriculares por professores como um campo de pesquisa que merece atenção na atualidade (DAVIS e KRAJCIK, 2005; REMILLARD, 2005; REMILLARD, HERBEL-EISENMANN e LLOYD 2009; BROWN, 2009). No Brasil, alguns estudos têm direcionado o foco para esse campo de pesquisa, como mostra Januario (2017).

Para Remillard (2009), entender a relação do professor com materiais curriculares de Matemática implica buscar compreender como os professores utilizam esses materiais, o que e como selecionam e planejam suas ações a partir desse uso, o que fazem com materiais curriculares e por que o fazem. Resulta, ainda, em estudos que visam entender se e como materiais 
curriculares podem influenciar as práticas de sala de aula.

No caso do Brasil, pesquisas com foco na relação entre professores e materiais curriculares são importantes para orientar políticas de elaboração e distribuição de livros didáticos e para balizar ações de formação inicial e continuada.

Neste artigo, temos por objetivo identificar conhecimentos mobilizados por professores que ensinam Matemática ao interagir com materiais curriculares.

Para desenvolvermos o estudo em torno desse objetivo, discutiremos algumas perspectivas teóricas sobre a relação professor-material curricular e o conhecimento do professor: Shulman (1986, 1987), Godino (2009) e Pino-Fan e Godino (2015). A partir dessa discussão elaboramos as categorias de análise deste estudo. Essa análise, por sua vez, é desenvolvida a partir do relatório de um projeto de pesquisa intitulado "Avaliação de professores do Ensino fundamental da Secretaria Municipal de Educação de São Paulo em relação a documentos e materiais de apoio à organização curricular na área de Educação Matemática", que foi desenvolvido com o intuito de compreender quais eram as contribuições que os materiais curriculares denominados Cadernos de Apoio e Aprendizagem de Matemática poderiam trazer para as experiências pedagógicas inovadoras das escolas dessa rede de ensino.

\section{Tipos de uso de materiais curriculares}

Para antendermos nosso objetivo de pesquisa, faz-se necessário compreender como se dá a relação do professor com os materiais curriculares e entender os usos que ele faz com esses materiais.

Sendo assim, compreender como os professores interagem com os recursos curriculares

[...] requer explicitar sobre as representações que os materiais curriculares usam para comunicar conceitos e ações, atentando 
para as formas em que os professores percebem e interpretam essas representações e compreender como essas representações podem restringir e propiciar a prática docente (BROWN, 2009, p. 18).

Isso está relacionado aos recursos curriculares e suas características, refere-se à forma como os estudos analisam o uso de materiais curriculares por professores e como os elaboradores criam os materiais que se destinam a influenciar a prática. No entanto, isso representa apenas uma parte da história, pois "compreender como as habilidades dos professores, os conhecimentos e crenças influenciam sua interpretação e utilização de materiais curriculares é fundamental para a compreensão da relação professor-ferramenta" (BROWN, 2009, p. 22).

Essa perspectiva também é proposta por Brown (2002) e Remillard (2005), que consideram materiais curriculares artefatos ou ferramentas culturais e enquadra como jogadores ativos tanto os materiais como os professores numa relação dinâmica e interativa. Desse modo, os professores tanto constroem seus próprios entendimentos de componentes curriculares quanto são influenciados por eles. Essa ideia está alicerçada na perspectiva de que ferramentas são "como 'produtos da evolução sociocultural' (WERTSCH, 1998), ambos moldam e são moldados pela ação humana por meio de suas affordances e restrições" (REMILLARD, 2005, p. 221). As affordances são aqui entendidas como possibilidades que os materiais curriculares oportunizam para seu uso. Estão relacionadas ao significado do objeto conectando percepção à ação e à cognição, envolvendo a adequação da interação entre indivíduo e objeto ou ambiente (JANUARIO, 2017).

Nesse sentido, Brown (2009) propõe o quadro The Design Capacity for Enactment (DCE) que enquadra as práticas curriculares docentes, os tipos de uso que fazem dos materiais curriculares como resultado da relação dinâmica entre as características dos recursos curriculares, por um lado, e, por outro, dos recursos que os professores trazem para essa relação.

Esse autor considera três tipos de uso dos materiais curriculares pelos 
professores: reprodução, adaptação e improvisação. Os próprios nomes relacionados aos tipos de uso elencados por Brown (2009) já sugerem os significados envolvidos. A reprodução refere-se ao uso que o professor faz de uma atividade proposta nos materiais curriculares conforme descrito pelos autores. A adaptação concerne às mudanças que os professores fazem nas atividades propostas pelos materiais. A improvisação diz respeito à tomada de decisão dos professores durante a aula para atender às ações espontâneas do estudante nas situações reais de sala de aula. Embora a improvisação possa se dar em uma prática com intencionalidade, ela não é planejada pelo professor.

\section{Conhecimento profissional docente}

Encontramos na literatura diversos modelos teóricos que buscam compreender os diferentes tipos de conhecimentos que os professores mobilizam ou que poderiam mobilizar ao desenvolver suas práticas de sala de aula e favorecer a aprendizagem de seus estudantes.

Um dos trabalhos pioneiros nessa perspectiva é o de Shulman (1986), que propôs inicialmente três categorias para o conhecimento do professor: conhecimento do conteúdo, conhecimento pedagógico do conteúdo $(\mathrm{PCK})^{3} \mathrm{e}$ conhecimento curricular. Posteriormente, em 1987, esse autor propôs sete categorias que incluem as três citadas anteriormente e mais quatro: conhecimento pedagógico geral, conhecimento dos estudantes e suas características, conhecimento dos contextos educativos e conhecimento dos objetivos, propósitos e valores da educação.

Enveredando pelas ideias de Shulman (1986, 1987), principalmente no tocante às categorias de conhecimento de conteúdo e conhecimento pedagógico de conteúdo, Godino (2009) propõe um sistema de categorias para analisar os conhecimentos dos professores de Matemática, Conhecimentos didático-

\footnotetext{
${ }^{3}$ A siglas PCK corresponde à expressão em inglês "Pedagogical Content Knowledge".
} 
matemáticos (CDM), que organiza, integra e estende outros modelos de conhecimentos dos professores, principalmente os propostos por Shulman $(1986,1987)$.

Esse modelo interpreta e caracteriza o conhecimento do professor a partir de três dimensões: dimensão matemática, dimensão didática e dimensão metadidático-matemática. Como o foco de nossa pesquisa centra-se nos conhecimentos mobilizados pelos professores ao se relacionarem com materiais curriculares, descrevemos as dimensões matemática e didática do CDM, uma vez que utilizamos algumas categorias dessas dimensões em nossa análise.

A dimensão matemática do conhecimento didático-matemático inclui duas subcategorias: (i) conhecimento comum do conteúdo; e (ii) conhecimento ampliado do conteúdo. A dimensão didática inclui seis subcategorias: (i) categoria epistêmica; (ii) categoria cognitiva; (iii) categoria afetiva; (iv) categoria interacional; (v) categoria mediacional; e (vi) categoria ecológica.

A categoria conhecimento comum do conteúdo do CDM refere-se ao conhecimento sobre um objeto matemático específico - por exemplo, função exponencial - necessário para resolver os problemas ou uma determinada tarefa proposta pelo próprio currículo de Matemática, pelo plano de estudos, pelos livros didáticos e/ou materiais curriculares para um nível específico de ensino - por exemplo, $1^{\circ}$ ano do Ensino Médio. Concerne, portanto, aos conhecimentos necessários para os professores e também para os estudantes.

O conhecimento ampliado do conteúdo alude ao conhecimento que o professor "precisa ter a respeito dos conteúdos matemáticos e de como eles estão relacionados, por exemplo, com os conteúdos matemáticos de outro nível de ensino" (RIBEIRO, 2016, p. 64). É esse conhecimento que dá base ao professor para identificar que a noção matemática que ele está trabalhando num determinado nível de ensino está relacionada a outros conteúdos ou noções matemáticas que os estudantes irão desenvolver em outros níveis posteriores. Consoante Pino-Fan e Godino (2015), esse conhecimento fornece ao professor as bases matemáticas necessárias para propor novos desafios 
matemáticos em sala, vincular o objeto matemático que se está estudando a outras noções matemáticas e a objetos matemáticos subsequentes ao próprio objeto que se está propondo no momento.

A categoria epistêmica da dimensão didática do CDM refere-se ao conhecimento matemático que o professor precisa ter para o ensino. Provido desse conhecimento ele pode ser capaz de proporcionar aos estudantes as diferentes representações de um objeto matemático que se pretende ensinar, resolver uma atividade ou uma determinada situação a partir de diferentes estratégias de resolução e procedimentos, relacionar um objeto matemático com outro do mesmo nível de ensino, ou com níveis anteriores e posteriores, compreender e mobilizar a diversidade de significados parciais para um mesmo objeto matemático ou a diversidade de conceitos que integram um determinado conceito, propiciar aos estudantes diferentes justificativas, argumentações e identificar os diferentes conhecimentos envolvidos na resolução de uma tarefa matemática (PINO-FAN e GODINO, 2015).

A categoria cognitiva do conhecimento didático-matemático refere-se ao conhecimento relacionado aos aspectos cognitivos dos estudantes. Com esse conhecimento, o professor, ao planejar uma situação de aprendizagem para seus estudantes e durante a ação em sala de aula, deve ser capaz de antecipar possíveis respostas dos estudantes, prever prováveis respostas, equívocos, conflitos e erros que surjam durante a resolução (PINO-FAN e GODINO, 2015).

A categoria afetiva do CDM está relacionada ao conhecimento necessário para compreender a disposição dos estudantes no sentido de apreender os aspectos que os motivam ou não a resolver um problema matemático ou a se envolver nas atividades matemáticas que lhes são proporcionadas.

A categoria interacional envolve os conhecimentos dos professores que são "necessários para prever, implementar e avaliar sequências de interações entre os agentes que participam do processo de ensino e aprendizagem orientados pela fixação e negociação de significados (aprendizagem) dos 
estudantes" (PINO-FAN e GODINO, 2015, p. 101). As interações podem ser estabelecidas entre professores e estudantes, estudantes e estudantes, estudantes e recurso e entre estudantes, recursos e professores.

A categoria mediacional diz respeito ao conhecimento que o professor precisa ter para fazer uso e avaliar os materiais e recursos tecnológicos para potencializar a aprendizagem dos estudantes sobre um objeto matemático específico, bem como saber adequar o tempo para as diferentes ações necessárias ao processo de aprendizagem.

A categoria ecológica refere-se aos conhecimentos sobre o currículo de Matemática do nível de ensino ao qual se refere o estudo de determinados conteúdos e objetos matemáticos, as relações que esse currículo nesse nível de ensino estabelece com outros currículos e com aspectos sociais, políticos e econômicos que apoiam e condicionam os processos de ensino e de aprendizagem.

\section{Contexto da investigação}

A busca por aportes teóricos que nos ajudassem a compreender e analisar os dados do relatório da pesquisa da qual participamos, intitulada "Avaliação de professores do Ensino Fundamental da Secretaria Municipal de Educação de São Paulo, em relação a documentos e materiais de apoio à organização curricular na área de Educação Matemática”, fez com que percebêssemos a necessidade de desenvolver uma metanálise desses dados.

A metanálise desenvolvida nessa investigação é fruto da análise do relatório de pesquisa, o qual passamos a descrevê-lo.

O projeto foi desenvolvido em parceria com os programas de pósgraduação na área de Educação Matemática da Pontifícia Universidade Católica de São Paulo (PUC-SP), da Universidade Cruzeiro do Sul (Unicsul) e Secretaria Municipal de Educação de São Paulo (SME-SP) sob a coordenação das pesquisadoras Célia Maria Carolino Pires e Edda Curi. O objetivo desse projeto foi analisar os impactos de documentos curriculares e 
cadernos de apoio e aprendizagem de Matemática elaborados pela SME-SP na prática e no desenvolvimento profissional de professores e apontar ajustes necessários a serem feitos para potencializar a aprendizagem dos estudantes.

Além das duas pesquisadoras responsáveis, o estudo contou com oito pesquisadores colaboradores que coordenavam as reuniões dos 31 professores da rede municipal, por agrupamentos correspondentes aos anos de escolaridade, $1^{\circ}$ ao $9^{\circ}$ ano do Ensino Fundamental, utilizando a metodologia de grupos focais. As reuniões eram realizadas aos sábados, com periodicidade quinzenal. No total do Projeto, os professores participaram de 104 horas de trabalho, com exceção do $4^{\circ}$ ano, por não haver inscrições de professores que atuassem nesse ano de escolaridade.

Nos encontros quinzenais, os professores agrupados por ano de escolaridade se reuniam com o pesquisador-colaborador responsável por aquele ano de escolaridade, analisavam conjuntamente as unidades de ensino do material curricular utilizado - Cadernos de Apoio à aprendizagem de Matemática (CAA) - planejavam seu desenvolvimento e no encontro seguinte relatavam como se deu, em suas salas de aula, esse desenvolvimento. Durante a realização de cada unidade, cada professor produzia dois relatórios do desenvolvimento de suas aulas com o uso do material. Em seguida, o pesquisador-colaborador de cada grupo elaborava um relatório síntese, das informações contidas nos relatórios dos professores.

Ao final do projeto, as pesquisadoras responsáveis reuniram os relatórios-síntese feitos pelos pesquisadores-colaboradores de cada agrupamento ( $1^{\circ}$ ao $9^{\circ}$ ano) e compuseram o relatório final, fonte de nossa coleta de dados. Objetivando identificar conhecimentos mobilizados por professores ao interagirem com materiais curriculares de Matemática, elencamos algumas categorias definidas a posteriori a partir do quadro teórico utilizado: conhecimento docente e a relação professor-material curricular para desenvolvermos a metanálise do relatório de pesquisa.

Em relação às categorias de análise, conforme mencionamos, há diferentes elementos envolvidos na relação que o professor estabelece com 
materiais curriculares de Matemática. Brown (2009) propõe um quadro em que se percebe os tipos de uso que os professores fazem com os materiais curriculares, que envolvem uma interação dinâmica entre os recursos dos próprios materiais e os recursos que os professores trazem para essa interação. Entre os elementos dos recursos dos professores, esse autor indica os conhecimentos de conteúdo e conhecimento pedagógico de conteúdo propostos por Shulman $(1986,1987)$. Nosso interesse para esse estudo situase nesses elementos relacionados aos recursos dos professores, mais especificamente aos conhecimentos mobilizados por eles ao se relacionar com materiais curriculares de Matemática.

Consideramos para elaborar nossas categorias de análise o modelo do Conhecimento Didático-Matemático (CDM) do conhecimento do professor proposto por Godino (2009), por entender que esse modelo incorpora as ideias propostas por Shulman $(1986,1987)$ e apresenta nuances mais específicas. Além disso, as categorias indicadas por Godino (2009) contêm outros conhecimentos que podem ser mobilizados pelo professor na relação com o material curricular e não mencionados no quadro exposto por Brown (2009). A partir dessa discussão e do quadro teórico apresentado, passamos ao desenvolvimento das categorias de análise, seguida da análise desenvolvida a partir do relatório do projeto de pesquisa.

Utilizamos para análise os tipos de uso que os professores fazem, ao se relacionar com materiais curriculares, propostos por Brown (2009): reprodução, adaptação e improvisação; e as categorias: epistêmica, cognitiva, mediacional, ecológica, de conhecimento comum e ampliado de conteúdo, propostas por Godino (2009).

A categoria afetiva do conhecimento didático-matemático não está expressa em nossas categorias de análise por não ter sido possível identificála a partir do relatório de pesquisa. A categoria de interação pôde ser observada no relatório, não na perspectiva de que os professores mobilizaram esse conhecimento, mas que o material propiciou esse conhecimento, por isso não foi incluída nessa análise. Organizamos um quadro (Quadro 1) para 
explicitar essas categorias, bem como uma síntese descritiva que nos fornece elementos para tal análise.

QUADRO 1: Categorias de análise e síntese descritiva

\begin{tabular}{|c|c|c|c|c|}
\hline & \multicolumn{2}{|c|}{ Categoria } & \multicolumn{2}{|c|}{ Síntese Descritiva } \\
\hline \multirow{3}{*}{ Tipos de uso } & \multicolumn{2}{|c|}{ Reprodução } & $\begin{array}{c}\text { Ao reproduzir } \\
\text { aquilo que está no } \\
\text { material o } \\
\text { professor o faz } \\
\text { intencionalmente } \\
\text { porque confia nos } \\
\text { materiais. }\end{array}$ & $\begin{array}{c}\text { Ao reproduzir } \\
\text { aquilo que está no } \\
\text { material o } \\
\text { professor o faz } \\
\text { intencionalmente } \\
\text { por não estar } \\
\text { seguro de suas } \\
\text { ações. }\end{array}$ \\
\hline & \multicolumn{2}{|c|}{ Adaptação } & $\begin{array}{c}\text { Os tipos de } \\
\text { adaptações que } \\
\text { foram feitas e se } \\
\text { essas adaptações } \\
\text { se aproximam das } \\
\text { ideias subjacentes } \\
\text { e propostas pelo } \\
\text { material } \\
\text { curricular. }\end{array}$ & $\begin{array}{c}\text { Ao desenvolver } \\
\text { suas aulas, o } \\
\text { professor adapta os } \\
\text { materiais } \\
\text { curriculares, mas } \\
\text { afasta-se das ideias } \\
\text { subjacentes e } \\
\text { propostas pelo } \\
\text { material. }\end{array}$ \\
\hline & \multicolumn{2}{|c|}{ Improvisação } & \multicolumn{2}{|c|}{$\begin{array}{c}\text { Situação que levou ao improviso e/ou tipo } \\
\text { de improviso feito }\end{array}$} \\
\hline \multirow{6}{*}{$\begin{array}{l}\text { Conhecimento } \\
\text { Didático- } \\
\text { Matemático }\end{array}$} & \multirow{4}{*}{$\begin{array}{l}\text { Dimensão } \\
\text { Didática }\end{array}$} & Epistêmica & \multirow{6}{*}{\multicolumn{2}{|c|}{$\begin{array}{c}\text { Exemplos encontrados no relatório de } \\
\text { pesquisa que mostram os conhecimentos } \\
\text { mobilizados pelos professores ao } \\
\text { reproduzirem, improvisarem ou } \\
\text { adaptarem o material curricular } \\
\text { utilizado }\end{array}$}} \\
\hline & & Cognitiva & & \\
\hline & & Mediacional & & \\
\hline & & Ecológica & & \\
\hline & \multirow{2}{*}{$\begin{array}{l}\text { Dimensão } \\
\text { Matemática }\end{array}$} & $\begin{array}{l}\text { Conhecimento } \\
\text { comum de } \\
\text { conteúdo }\end{array}$ & & \\
\hline & & $\begin{array}{l}\text { Conhecimento } \\
\text { ampliado de } \\
\text { conteúdo }\end{array}$ & & \\
\hline
\end{tabular}

Fonte: Elaboração das Autoras

\section{Conhecimentos do professor que ensina Matemática e tipos de uso de materiais curriculares}

Neste tópico temos o propósito de identificar os tipos de usos que os professores que ensinam Matemática fazem ao se relacionar com materiais 
curriculares, observando os conhecimentos por eles mobilizados a partir desse uso e/ou identificando a mobilização dos conhecimentos do professor propiciados pela sua relação com os materiais. Apresentamos, por tanto, recortes do relatório de pesquisa e em seguida as análises referentes a eles.

No excerto a seguir identificamos duas formas de práticas a partir do uso dos materiais curriculares - Cadernos de Apoio e Aprendizagem de Matemática (CAA):

O professor [...] destacou outra observação importante: por entender que um dos principais objetivos do CAA é explicitar a relação entre um conjunto de atividades e as expectativas de aprendizagem que se pretende alcançar. Esse conjunto de atividades ora se constitui numa sequência de atividades, ora numa sequência didática, mas sempre com o objetivo de levar o estudante a construir uma ideia ou procedimento matemático. Assim, esse professor vê que os Cadernos não possuem a característica de ser um material com o objetivo de possuir atividades de fixação de conteúdos trabalhados e, assim sendo, para todas as expectativas de aprendizagem, há necessidade de uma complementação (Relatório de Pesquisa, fragmento referente ao grupo dos professores do $6^{\circ}$ ano do Ensino Fundamental, p. 93).

Os professores do $6 .^{\circ}$ ano, ao fazerem esse relato, mostram que percebem as ideias subjacentes nos materiais referentes à forma como as atividades são propostas para que os estudantes construam as ideias/conceitos matemáticos. Com isso, eles desenvolvem suas aulas começando com as situações de aprendizagem propostas nos materiais e na sequência apresentam atividades de fixação. Em um determinado momento, esses professores reproduzem em suas salas de aula aquilo que está referenciado nos materiais e, em outro momento, fazem adaptações ao inserirem atividades que complementam as que estão postas nos materiais.

Observamos que, ao reproduzir aquilo que está nos materiais, esses 
professores o fazem intencionalmente a partir de uma análise prévia das situações de aprendizagem e por conceberem atividades desenvolvidas com o objetivo de que o estudante construa suas próprias aprendizagens. Quanto às atividades de fixação que os professores acrescentam ao desenvolver suas aulas, caracterizam adaptações feitas do material, porém que se aproximam da ideia original. Isso foi possível perceber a partir da comparação que fizemos entre as atividades acrescidas pelos professores que constam no relatório e as atividades dos CAA referentes à unidade I, as quais foram citadas no excerto supra. Ressaltamos que no início do projeto os professores tinham a ideia de que os CAA eram um complemento para as atividades desenvolvidas pelo professor, principalmente iniciadas com o livro didático. No decorrer do projeto, foram percebendo que as atividades propostas no material eram para ser trabalhadas como "um pontapé" inicial para o desenvolvimento dos conceitos e conteúdos a serem construídos pelos alunos. Portanto, começaram a fazer o inverso, as atividades dos livros didáticos passaram a servir como complemento às atividades dos Cadernos de Apoio e Aprendizagem. Ao identificarem, as concepções dos materiais curriculares e ao acrescentarem atividades que convergem com as ideias originais dos materiais, os professores mobilizam conhecimentos relacionados ao conteúdo matemático propostos nessas atividades. No entanto, muito além desse conhecimento, perceberam, como vimos no excerto, a concepção do material, a metodologia envolvida nessa sequência de aprendizagem, os tipos de atividade que eram propostas, os procedimentos e estratégias de resolução envolvida, conhecimentos necessários para o ensino de um determinado conteúdo matemático, o qual classificaríamos na categoria epistêmica do Conhecimento Didático-Matemático a partir das ideias de Pino-Fan e Godino (2015).

Nas sequências de aprendizagem, proposta nos CAA de Matemática, os autores definem previamente a expectativa de aprendizagem relacionada a essas atividades. Ao planejar suas aulas e avaliar se as atividades propostas correspondem de fato às expectativas de aprendizagem relacionadas a elas, os professores precisam perceber os conhecimentos matemáticos envolvidos 
nessas atividades, bem como seus objetivos, principalmente se eles tinham intenções ou percebessem a necessidade de adicionar atividades e que estas não fossem contrárias aos objetivos dos materiais.

As expectativas propostas estavam adequadas às sequências de atividades, porém havia algumas expectativas que apareceram nas sequências e que não estavam previstas na abertura da unidade como: Ler números pela compreensão das características do Sistema de numeração decimal que aparece na atividade 3 Linhas de ônibus (Relatório de Pesquisa, fragmento referente ao grupo dos professores do $3^{\circ}$ ano do Ensino Fundamental, p. 36).

Relatos como esse mostram a análise que os professores fazem para perceber se de fato as tarefas propostas se relacionam às expectativas de aprendizagem. Tais análises enquadram-se na categoria epistêmica do conhecimento didático-matemático. Essa tarefa parece simples, mas exige muitas demandas do professor, e, conforme relatório de pesquisa, as dificuldades foram identificadas principalmente quando o professor precisou selecionar atividades que complementassem as atividades propostas pelos materiais, mas que cumprissem os mesmos objetivos e perspectivas. Vale ressaltar que essa comparação entre a expectativa de aprendizagem e as atividades era um dos questionamentos que os professores precisavam responder como forma de avaliação de cada unidade do Caderno de Apoio e Aprendizagem (CAA).

No exemplo a seguir foi possível distinguir dois tipos de usos que os professores fazem ao desenvolver uma situação de aprendizagem presente no CAA:

Nas atividades relativas ao ditado de números - Cuidando dos dentes - houve intervenções diferentes a partir do conhecimento que a turma apresentou. Um dos professores chamou a atenção em relação à posição dos números, ou seja, se tivermos o 14 e 41, eles 
estão invertidos em suas posições, o 1 representa na primeira escrita a dezena e na outra a unidade, o mesmo se deu com o 4 na primeira escrita ele representa a unidade, na segunda ele representa a dezena e, consequentemente, representam quantidades diferentes. Em outra turma que os alunos apresentaram dificuldade no trabalho com os agrupamentos a professora [...] aproveitou para chamar a atenção dos agrupamentos de 10 que os alunos poderiam fazer, ao analisar o 14, eles verificaram que no 14 há 1 agrupamento de 10 e 4 unidades, no 41 temos 4 agrupamentos de 10 e apenas 1 unidade (Relatório de Pesquisa, fragmento referente ao grupo dos professores do $2^{\circ}$ ano do Ensino Fundamental, p. 33).

Os professores analisaram a expectativa de aprendizagem referente às respectivas atividades e perceberam que estas refletem os objetivos pretendidos, por isso decidiram reproduzir a atividade como proposta pelos materiais. Mesmo reproduzindo, durante sua atuação em sala de aula, os professores precisam tomar decisões a partir de suas percepções sobre as aprendizagens dos estudantes, que implicam improvisações. Por exemplo, a atividade referida pelos professores do $2 .^{\circ}$ ano sugere que os professores explorem a posição dos algarismos na escrita dos números. Cada professor faz essa exploração, mas são decisões diferentes, pois o professor de uma turma explora a partir da posição do número no quadro valor de lugar e a outra professora explora a partir dos agrupamentos.

No relato a seguir podemos observar que os professores solicitam mais atividades antes do desenvolvimento da sequência proposta no CAA, portanto fazem adaptações nos materiais:

$\mathrm{Na}$ unidade como um todo os professores salientam que outras atividades envolvendo as operações com números racionais, porcentagem, parte-todo, razão, proporção e frações equivalentes poderiam ser introduzidas: "Apesar das atividades propostas 
estarem de acordo com expectativas e aprendizagem pude observar que dois assuntos foram de máxima relevância nessa unidade, não se esgotando as atividades propostas, pois tive que trabalhá-las mais profundamente, foram as operações com números racionais na forma fracionária e o cálculo de porcentagem [...] Acredito que devam existir previamente atividades que trabalhem comparação entre parte-todo, um número, uma razão, um quociente ou divisão indicada, um operador de uma quantidade ou medida, frações equivalentes. Não só nas atividades (p. 20-21-22), mas as explicações também, por se tratar de um assunto que gera grandes discussões nos erros cometidos por nossos estudantes e até de professores" (Relatório de Pesquisa, fragmento referente ao grupo dos professores do $8^{\circ}$ ano do Ensino Fundamental, p. 157).

A sequência de atividades mencionadas no excerto envolve os números racionais e objetiva uma revisão daquilo que é proposto em anos anteriores. Por perceberem que se trata de conteúdos em que os alunos sentem dificuldades, os professores relatam a necessidade de atividades que antecedam as que estão propostas e que foi necessária a inserção de outras para aprofundar o conteúdo abordado, caracterizando assim uma adaptação ao material curricular. Fica implícito no excerto que os professores, apesar de terem incluído atividades, desenvolveram as atividades propostas pelos materiais, portanto reproduziram as atividades. Apesar de, pelo relatório, percebermos implicitamente a reprodução, sabemos que ela ocorreu, pois durante o projeto de pesquisa os professores desenvolviam todas as sequências de aprendizagem propostas pelos CAA, mesmo que para isso acrescentassem outras atividades ou explicações. $\mathrm{O}$ que não podemos garantir é se essas reproduções atendem ou não aos objetivos dos materiais.

Observamos que, ao adaptarem e reproduzirem as situações de aprendizagem presentes nos materiais curriculares, os professores, por um lado, mostram, a partir de suas experiências em sala de aula, que o estudo desses objetos matemáticos gera muitas dúvidas nos estudantes e erros 
frequentemente cometidos por eles. Percebemos, então, a mobilização dos conhecimentos relacionados à categoria cognitiva. Por outro lado, mobilizam conhecimentos relacionados ao conteúdo matemático em si, referentes à categoria de conhecimento comum de conteúdo, mas com preocupações voltadas para o ensino, portanto referente à categoria epistêmica. Identificamos a mobilização de conhecimentos relacionados à categoria epistêmica ao percebermos que os professores conhecem os significados parciais de um dado objeto matemático, das diferentes representações e estratégias de resolução das atividades. A categoria epistêmica envolve o conhecimento matemático que o professor necessita para o ensino, dessa forma o professor deve ser capaz, entre outras coisas, de "compreender e mobilizar a diversidade de significados parciais para um único objeto matemático" (PINO-FAN e GODINO, 2015, p. 99).

Identificamos também a mobilização de conhecimentos relacionados à categoria epistêmica no tocante aos significados parciais de um determinado objeto matemático e da importância das diferentes estratégias de resolução para uma determinada atividade no excerto a seguir:

As atividades relativas à expectativa M9 procuram consolidar, por meio de situações-problema, os diferentes significados do campo aditivo já vistos no Ciclo I, ao mesmo tempo que exploram diferentes estratégias de resolução envolvendo cálculos exatos, aproximados e o uso da calculadora.

Para os professores, nessa unidade os conhecimentos matemáticos foram explorados de modo contextualizado, com situações-problema do cotidiano do aluno, por meio de uma rede de significados matemáticos e em outras áreas do conhecimento (Relatório de Pesquisa, fragmento referente ao grupo dos professores do $6^{\circ}$ ano do Ensino Fundamental, p. 92).

Ao explicitarem a importância do contexto em que as atividades estão inseridas, tanto as aplicações no cotidiano quanto em outras áreas do saber, 
os professores percebem articulações entre os conteúdos matemáticos e aspectos sociais mobilizando, assim, conhecimentos relacionados às discussões curriculares concernentes à função social da matemática escolar, associados à categoria ecológica do CDM.

Os excertos seguintes mostram que os professores reproduziram aquilo que está nos CAA, mas essa reprodução foi intencional por compreender que as diferentes linguagens e representações de um mesmo objeto matemático propostas nas sequências de aprendizagem, bem como a possibilidade de utilizar conhecimentos prévios, favorecem a construção do conhecimento matemático pelo estudante.

Os professores do $7^{\circ}$ ano apontaram como positiva a iniciativa das atividades em que é solicitada ao aluno a construção de tabelas a partir de dados contidos em gráficos. Pois, segundo eles, os estudantes estão mais acostumados a fazer o inverso, ou seja, da tabela para o gráfico. Por isso justificam uma maior dificuldade nesse tipo de atividade, por parte dos estudantes (Relatório de Pesquisa, fragmento referente ao grupo dos professores do $7^{\circ}$ ano do Ensino Fundamental, p. 136).

Segundo os professores, as atividades Razão entre segmentos de reta, Relacionando medidas e Razões entre medidas de segmentos (páginas 74 a 78/livro do aluno - volume único), mobilizam vários conceitos e saberes estudados anteriormente. Aspectos que podem contribuir para a aprendizagem dos estudantes, pois partem do que ele já estudou para propor outros conceitos e procedimentos. Além disso o aluno precisa mobilizar estratégias para resolução da atividade (Relatório de Pesquisa, fragmento referente ao grupo dos professores do $9^{\circ}$ ano do Ensino Fundamental, p. 197).

Ao planejarem e desenvolverem suas aulas, os professores interpretaram aquilo que estava presente nos materiais e decidiram reproduzir. Observamos que para essa decisão eles mobilizam conhecimentos 
de conteúdos matemáticos que pretendem trabalhar com os seus alunos, portanto mobilizam conhecimentos referentes à dimensão matemática no tocante à categoria de conhecimento comum de conteúdo e, em destaque para o excerto do $9^{\circ}$ ano na atividade envolvendo razão, identificamos a preocupação dos professores com as conexões entre os conteúdos matemáticos que podem ser no mesmo nível de ensino ou a relação entre conteúdos abordados em níveis de ensino diferentes. Esse fato revela a dimensão matemática do CDM relacionada ao conhecimento ampliado de conteúdo.

Vale ressaltar que os conhecimentos de conteúdo matemáticos identificados nos excertos estão atrelados a outros conhecimentos que envolvem a categoria epistêmica do conhecimento didático-matemático, por exemplo, ao se preocuparem com as conversões do gráfico para tabela e viceversa (excerto do $7^{\circ}$ ano) e ao perceberem que os alunos precisam utilizar diferentes estratégias de resolução para uma determinada tarefa e de vários conceitos para compreenderem um objeto matemático (excerto do $9^{\circ}$ ano).

Esses relatos evidenciam, além dos conhecimentos matemáticos para o ensino, como mencionado anteriormente, como os professores mobilizam conhecimentos relacionados a aspectos cognitivos dos estudantes - dimensão cognitiva do CDM. Por exemplo, no excerto do $9^{\circ}$ ano os professores perceberam os aspectos que favorecem a aprendizagem dos alunos, e os professores do $7^{\circ}$ ano já sabiam das principais dificuldades dos estudantes relativas às diferentes representações, e, a partir da mobilização dos conhecimentos de seus alunos, sentem a necessidade de reproduzir aquilo que está no material, pois identificam que as atividades propostas focam exatamente a superação dessas dificuldades.

Nos excertos a seguir também foi possível perceber que os professores improvisam ao desenvolver as situações de aprendizagem, mas também temos evidência da reprodução, pois foi ao reproduzir as atividades que os professores precisaram tomar decisões imediatas em determinados momentos. 
$\mathrm{Na}$ atividade "Índice de Massa Corporal", p. 19, foi necessário explicar na lousa como se desenvolvem as aproximações das casas decimais, e também apresentar um exemplo de como se faz o cálculo do IMC (Relatório de Pesquisa, fragmento referente ao grupo dos professores do $7^{\circ}$ ano do Ensino Fundamental, p. 131).

Desenvolver situações de aprendizagem propostas em um currículo apresentado em situações reais de sala de aula envolve necessariamente a tomada de decisão dos professores durante a aula. Brown (2009) tem se referido a essa atividade como o trabalho de improvisação. Essa atividade também exige que o professor utilize seus próprios recursos e os coloque em ação a fim de criar contextos de intervenção. Na atividade citada no excerto do $7^{\circ}$ ano, a ideia era verificar se os estudantes percebem que o cálculo do IMC envolve as operações multiplicação e divisão, mas, ao apresentar um exemplo na lousa de como se faz o cálculo, o professor já identifica para o estudante as operações envolvidas na atividade. Portanto, a improvisação que o professor fez, inserindo um exemplo antes de os estudantes desenvolverem as atividades, divergiu da proposta original dos materiais. Observa-se também que os professores precisam explicar como são feitas as aproximações de casas decimais. Esse improviso foi necessário, pois os professores notaram que os estudantes não conseguiriam desenvolver sozinhos essas aproximações solicitadas na atividade 2. Nesse caso, não houve divergência em relação aos objetivos pretendidos pelos materiais, pois essa atividade tinha por objetivo explorar os diferentes significados de um número racional. Os professores foram capazes de perceber as dificuldades apresentadas por seus estudantes a partir de conhecimentos relacionados aos aspectos cognitivos deles dimensão cognitiva do CDM -, e esse conhecimento docente foi possível de ser mobilizado a partir da própria experiência em sala de aula.

Temos algumas evidências no relatório de pesquisa de que alguns professores adaptam os materiais curriculares, mas transformam os objetivos pretendidos pelos materiais de modo a atender seus próprios objetivos de 
ensino.

A professora [...] relata as complementações que necessárias para a aprendizagem dos estudantes da seguinte forma: "Em relação às atividades com frações e operações com decimais, trabalhamos de certa forma tranquila, o que teve maior dificuldade foi na soma e subtração de números fracionários, uso do MMC,[...]. Não houve muito interesse nas atividades de razão e proporção, achei que os exemplos não foram bem escolhidos e tive que adicionar exemplos adotados em livros didáticos, depois aproveitei para explicar regra de três simples e razões, achei que no CAA os exemplos poderiam ser mais simples" (Relatório de Pesquisa, fragmento referente ao grupo dos professores do $7^{\circ}$ ano do Ensino Fundamental, p. 148).

O professor [...] faz a retomada do conteúdo que está sendo trabalhado no momento. Uma revisão. Segundo ele "Abre uma janelinha" (Relatório de Pesquisa, fragmento referente ao grupo dos professores do $9^{\circ}$ ano do Ensino Fundamental, p. 193).

Percebemos que esses professores adaptam os materiais curriculares, acrescentando exemplos e/ou revisões antes de iniciarem a sequência de atividades apresentadas pelo material. Os Cadernos de Apoio e Aprendizagem (CAA) propõem que os estudantes desenvolvam as situações de aprendizagem como ponto de partida para a construção do conhecimento de um determinado conceito/ideia ou conteúdo matemático. Portanto, a concepção subjacente aos materiais é contrária à ideia de apresentação e abordagem de conteúdos a partir de definições, seguidos de exemplos e exercícios. Ao fazerem revisões antes e utilizar as sequências do material curricular como exercícios para abordagens ou revisões feitas previamente, os professores se distanciam das ideias originais desses materiais.

Identificamos, ainda, no relatório de pesquisa que os professores utilizam recursos materiais, artefatos para potencializar a aprendizagem de determinados conteúdos matemáticos por parte de seus estudantes. Ao fazer 
essa avaliação de que artefatos são essenciais, os professores mobilizam conhecimentos necessários para o ensino, os quais estão relacionados à categoria de mediação do CDM.

Para as sequências de atividades que envolvem os sólidos geométricos e as figuras planas, a professora [...] e o professor [...] levaram para sala de aula os sólidos para que os estudantes manipulassem o material, isso favoreceu aos estudantes a estabelecerem as relações entre o número de lados, vértices, faces e arestas com o número de lados do polígono da base e trouxe indicações ao professor dos conhecimentos prévios dos estudantes (Relatório de Pesquisa, fragmento referente ao grupo dos professores do $7^{\circ}$ ano do Ensino Fundamental, p. 132).

A partir de suas experiências, os professores conhecem as dificuldades dos estudantes em relação à abstração. Por isso, identificam quais as necessidades deles: manipular artefatos. Os professores sabem que a manipulação de artefatos permite a percepção de características e propriedades que apenas pela representação figural não seria possível. O tipo de uso que o professor fez com o material curricular nesse caso foi caracterizado por uma adaptação, em que o professor utiliza materiais manipuláveis antes do início da atividade proposta pelo material. Esse uso não contradiz as ideias originais do material curricular. Também fica evidente a categoria cognitiva do conhecimento didático-matemático, pois os professores mobilizam conhecimentos relacionados à aprendizagem dos estudantes.

Esses último excertos envolvendo também a categoria de mediação nos mostra o quanto os professores mobilizam seus conhecimentos para usar e avaliar a importância da utilização de recursos disponíveis como calculadora, softwares, sólidos geométricos, entre outros, para potencializar a aprendizagem dos estudantes. 


\section{Ideias finais}

Os professores que ensinam Matemática desenvolvem uma variedade de práticas ao utilizar os materiais curriculares e, a partir desse uso, mobilizam seus próprios recursos, conhecimentos para desenvolver suas aulas. Partindo dessa ideia, entendemos o professor não como mero implementador daquilo que os recursos curriculares apresentam, mas como alguém que, a partir de seus conhecimentos, experiências e crenças, interpreta, modifica, redesenha, adapta aquilo que está presente nos materiais curriculares a situações reais de sala de aula. Assim como Brown (2009), observamos que em momentos diferentes e em situações distintas os professores reproduzem, adaptam e improvisam a partir do uso que fazem dos materiais curriculares.

Com base nos conhecimentos que os professores mobilizam a partir dos tipos de usos que fazem dos materiais curriculares, percebemos que os professores em determinados momentos confiam nos materiais curriculares, nas atividades propostas, na sequência em que essas atividades são propostas, nos enunciados, e, acabam por reproduzir aquilo que está nos materiais. Nesse caso, confiar nos materiais representa uma decisão estratégica do professor por entender os objetivos dos materiais curriculares em consonância com os seus próprios objetivos de ensino.

Nesse caso, em que determinam a reprodução, eles confiavam nos materiais curriculares e deslocam a agência aos materiais para orientar e desenvolver suas aulas. A agência é aqui entendida como aquele que tem autoridade, quem é o agente ou quem age sobre as decisões curriculares.

A noção de reprodução pode ser derivada da visão de que "a inteligência pode ser distribuída entre pessoas e artefatos, e que as pessoas podem confiar em artefatos para atingir seus objetivos" (PEA, 1993 apud BROWN, 2009, p. 25). Nenhum tipo de uso que o professor faz pode ser considerado superior ao outro; nesse caso a reprodução pode ser uma decisão estratégica por parte do professor, e não uma indicação de deficiência. A escala de reprodução, 
adaptação e improvisação caracteriza a natureza da interação de um professor com um determinado recurso, mas não avalia os resultados dessa interação.

Ao analisarmos o relatório de pesquisa, conseguimos perceber que alguns professores, em certos momentos, ao decidirem pela reprodução, o faziam intencionalmente a partir de suas reflexões e atribuíam agência aos materiais curriculares, e, ao desenvolverem suas aulas, a reprodução convergia com as ideias originais dos elaboradores dos materiais. No entanto, a reprodução feita por alguns professores não resultava nos objetivos pretendidos pelos que planejaram os materiais. Houve ainda situações em que os professores usavam os materiais de forma literal, mas não foi possível concluir se o resultado desse tipo de uso convergia ou não com os objetivos pretendidos pelos materiais curriculares. Nesses casos, identificamos que só a partir de pesquisas empíricas com observação do desenvolvimento das aulas do professor com a utilização dos materiais seria possível observar esse tipo de resultado, o que apresenta perspectivas para novas pesquisas.

Outro tipo de uso caracterizado por Brown (2009), e que observamos em nossos estudos, refere-se à adaptação e à improvisação. Nas adaptações os professores modificam aquilo que está recomendado nos materiais curriculares. Ao tomarem essa decisão, os professores atribuem agência tanto aos materiais, quanto a eles mesmos, pois mobilizam seus conhecimentos e decidem adaptar os materiais. No caso das situações de improviso, os professores atribuem agência muito mais a eles mesmos do que aos materiais, pois precisam agir nas situações reais de sala de aula para responder a uma necessidade ou as ações espontâneas de seus estudantes. Desse modo, tomam decisões durante a aula, mesmo que estas não tenham sido planejadas.

A nosso ver, ao adaptarem os materiais, os professores têm maior capacidade de design, em uma relação que Remillard (2005) caracteriza como infidelidade curricular. Nesses casos, parece que eles mobilizam mais seus próprios recursos a fim de atingir seus objetivos de ensino, mas nem sempre isso é verdade. 
Em nossos estudos, conseguimos avaliar, a partir do relatório de pesquisa, os resultados das adaptações que os professores fizeram ao se relacionarem com os materiais curriculares. Observamos, por exemplo, em alguns momentos, que os professores adicionam atividades ao final das tarefas propostas pelo material e essa adaptação converge com a ideia dos elaboradores. Entretanto, em outros momentos não foi possível avaliar o resultado dessa inclusão, sendo necessário que eles tivessem explicitado as tarefas que inseriram, mas isso só foi claro em algumas partes do relatório.

Ao inserir atividades e/ou abordagens antes de iniciar as atividades propostas pelo material, observamos dois tipos de resultados das adaptações feitas. Os materiais utilizados propõem situações de aprendizagem em que o estudante vai desenvolvendo as atividades a partir da resolução de problemas, exploração, investigação, observação de padrões etc. para construir o conhecimento matemático que se pretende. Em vez disso, relato de alguns professores nos mostra que a adaptação dos materiais curriculares, principalmente ao inserir tarefas anteriores nos materiais, cabe noções tradicionais ao desenvolver suas aulas. Contrários à proposta dos $\mathrm{CAA}$, os professores explicam o conteúdo/conceito abordado, apresentam exemplos e utilizam as atividades propostas no material como exercícios. Encontramos também alterações no início das atividades propostas que convergem com a ideia original dos materiais. Nesse caso, os professores inserem atividades com a intenção de captar os conhecimentos prévios dos estudantes para então começar a desenvolver as atividades propostas.

A distinção entre as decisões do professor que envolvem reproduções, adaptações e improvisações, bem como os resultados dessas decisões, revelam as diferentes formas pelas quais os materiais podem contribuir e apoiar a prática de sala de aula do professor. Ao tomar essas decisões, os professores mobilizam seus próprios recursos, consideram os objetivos do ensino, as necessidades dos estudantes, a melhor forma de utilizar os materiais para alcançar os resultados desejados. Refletir sobre o material que está utilizando, definir como vai usá-lo, seja reproduzindo, adaptando ou 
improvisando, requer dos professores a mobilização de seus próprios conhecimentos para desenvolver suas ações nas situações de sala de aula.

Em relação aos recursos que os professores disponibilizam ao interagir com materiais curriculares, percebemos nessa análise que eles mobilizam seus conhecimentos de conteúdo, mas, muito além de conhecimento matemático, mobilizaram conhecimentos referentes ao ensino de Matemática, bem como sobre os aspectos cognitivos dos estudantes, a importância da função social da matemática e do uso de recursos curriculares.

Essa mobilização por vezes parte do próprio professor. Ao definir que irão reproduzir, adaptar ou improvisar com os materiais disponíveis, os professores, a partir de suas experiências de sala de aula, mobilizam seus conhecimentos, os quais redesenham os recursos curriculares para colocá-los em ação na sala de aula. Como vimos pela análise, esses conhecimentos estavam imbricados naqueles que enquadraríamos nas categorias epistêmica, cognitiva, ecológica, mediacional e de conhecimento comum e ampliado de conteúdo do CDM. A categoria que mais se sobressaiu na mobilização dos conhecimentos do professor foi a epistêmica, aquela que envolve o conhecimento matemático para o ensino, ou seja, muito além da necessidade do conhecimento matemático do conteúdo, os professores preocupavam-se com a relação desses conteúdos com o ensino. Daí a importância de os materiais curriculares apoiarem os professores nessa mobilização dos conhecimentos.

A ideia de que o uso de recursos curriculares por professores de Matemática é um processo de design e percebendo que os conhecimentos mobilizados pelos professores ao utilizar os materiais curriculares expressamse principalmente nas categorias epistêmica e cognitiva, e em maior escala na dimensão epistêmica, inferimos a necessidade de que os materiais curriculares possam ser pensados e elaborados para atender a essas demandas dos professores, que sejam concebidos de modo a apoiar principalmente a mobilização desses conhecimentos.

\section{Referências}


BROWN, Matthew William. Teaching by design: understanding the interaction between teacher practice and the design of curricular innovations. 2002. 543f. Tese (Doutorado em Ciências da Aprendizagem) - School of Education \& Social Policy, Northwestern University, Evanston, Illinois (EUA).

BROWN, Matthew William. The Teacher-Tool Relationship: Theorizing the Design and Use of Curriculum Materials. In: REMILLARD, Janine. T; HERBELEISENMANN, Beth A.; LLOYD, Gwendolyn Monica. (Ed.). Mathematics Teachers at Work: connecting curriculum materials and classroom instruction. New York: Taylor \& Francis, 2009. p. 17-36.

DAVIS, Elizabeth; KRAJCIK, Joseph. Designing Educative Curriculum Materials to Promote Teacher Learning. Educational Researcher, v. 34, n. 3, p. 3-14, 2005.

GODINO, Juan Diaz. Categorías de análisis de los conocimientos del Profesor de Matemáticas. Unión: Revista Iberoamericana de Educación Matemática, n. 20, p. 1331,2009 .

JANUARIO, Gilberto. Marco conceitual para estudar a relação entre materiais curriculares e professores de Matemática. 2017. 194f. Tese (Doutorado em Educação Matemática). Faculdade de Ciências Exatas e Tecnologia. Pontifícia Universidade Católica de São Paulo. São Paulo.

LLOYD, Gwendolyn Monica; REMILLARD, Janine T.; HERBEL-EISENMANN, Beth A. Teachers' Use of Curriculum Materials: An Emerging Field. In: REMILLARD, Janine T.; HERBEL-EISENMANN, Beth A.; LLOYD, Gwendolyn Monica. (Ed.). Mathematics Teachers at Work: Connecting curriculum materials and classroom instruction. New York: Taylor \& Francis, 2009, p. 3-14.

PINO-FAN, Luis Roberto; GODINO, Juan Diaz. Perspectiva ampliada del Conocimiento Didáctico-Matemático del professor. Paradigma, v. 36, no. 1, 2015, p. 87-109.

PINO-FAN, Luis Roberto; GODINO, Juan Diaz; FONT, Vicenç. Diseño y aplicación de un instrumento para explorar la faceta epistémica del conocimiento didácticomatemático de futuros profesores sobre la derivada. Revemat, Florianópolis, v. 8, n.2, 2013, p. 1-49.

REMILLARD, Janine T. Examining key concepts in research on teachers'use of Mathematics Curricula. Review of Educational Research, Washington, American Educational Research Association, v. 75, n. 2, p. 211-246, jun. 2005.

REMILLARD, Janine T.; HERBEL-EISENMANN, Beth A.; LLOYD, Gwendolyn Monica. (Ed.). Mathematics Teachers at Work: Connecting Curriculum Materials and Classroom Instruction. New York: Taylor e Francis, 2009.

RIBEIRO, Rogério Marques. Modelagem Matemática e mobilização de conhecimentos didático-matemáticos na formação continuada de professores dos anos iniciais. 2016. 262f. Tese (Doutorado em Educação) - Programa de Pós-Graduação em Educação, Universidade Federal de São Carlos, São Carlos. 
SÃO PAULO (Município). Secretaria Municipal de Educação. Diretoria de Orientação Técnica. Caderno de Apoio e Aprendizagem: Matemática, 1ao $9^{\circ}$ ano, versão do professor. São Paulo: SME/DOT, 2010.

SCHNEIDER, Rebeca M.; KRAJCIK, Josep. Supporting Science Teacher Learning: The Role of Educative Curriculum Material. Journal of Science Teacher Education, New York, v. 13, n. 3, p. 221-245, 2002.

SHULMAN, Lee S. Knowledge and teaching: foundations of the new reform. Harvard Educational Review, Harvard University, Cambridge, v. 57, n. 4, p. 1-22, 1987.

SHULMAN, Lee S. Those Who Understand: Knowledge Growth in Teaching. Educational Researcher, American Educational Research Association, Washington, v. 15 , n. 2 , p. $4-14$, fev. 1986.

STEIN, Mary Kay; KIM, Gooyeon. The Role of Mathematics Curriculum Materials in Large-Scale Urban Reform: An Analysis of Demands and Opportunities for Teacher Learning. In: REMILLARD, Janine T.; HERBEL-EISENMANN, Beth A.; LLOYD, Gwendolyn Monica. (Ed.). Mathematics Teachers at Work: Connecting curriculum materials and classroom instruction. New York: Taylor \& Francis, 2009, p. 37-55. 